\title{
Testimonios y narraciones para comprender y resignificar el terremoto del 27 de febrero. Aproximación a las experiencias autobiográficas de una generación de jóvenes chilenos.
}

\author{
Stories and narratives for understanding and meaning \\ February 27's earthquake. \\ Approach to the autobiographical experiences of a \\ generation of young Chileans
}

GABRIEla RuBILAR

Gabriela Rubilar es doctora en Ciencias Humanas y Sociales de la Universidad Pontificia de Comillas; actualmente es académica de la Escuela de Trabajo Social UC. Su dirección electrónica es grubilad@uc.cl; su dirección postal es Av. Vicuña Mackenna 4860, Macul - Campus San Joaquín.

\begin{abstract}
Resumen
Este artículo, a través del método biográfico-interpretativo, da cuenta de la reconstrucción de experiencias e impresiones de un grupo de estudiantes universitarios sobre el terremoto sufrido en Chile en Febrero del año 2010. Esta reconstrucción se realizó por medio de una autoentrevista que intencionaba tres momentos de la experiencia: antes, durante y después del desastre. El mismo esquema fue seguido posteriormente por los mismos estudiantes quienes entrevistaron a una persona afectada por el terremoto. El grado de afectación fue determinado por los propios alumnos, quienes privilegiaron aspectos emocionales y psicológicos, por sobre otras dimensiones que daban cuenta de pérdidas y daños en viviendas, u otro tipo de situación producto de esta catástrofe. El análisis de estos ejercicios da cuenta de una primera aproximación descriptiva interpretativa de los relatos de alumnos y afectados, la que se espera complementar en futuras investigaciones.
\end{abstract}

Palabras Claves. Memoria, autoentrevista, terremoto, afectados, desigualdad.

\begin{abstract}
This article, through a biographical-interpretive method, presents the reconstruction of experiences and impressions of a group of university students that, applying a self-interview, talked about their experiences about the earthquake occurred in Chile in February 2010. The presented versions were oriented in three times: before, during and after the disaster. Subsequently, the same pattern of interview was followed by the students, who interviewed a person affected by the earthquake. The degree of suffering was determined by the students themselves, who privileged the emotional and psychological dimensions over others related to losses and damage in housing, or other situation brought by this disaster. The analysis of these exercises gives account of a first descriptive and interpretative approach of the stories of students and other people affected; it is expected to complement these findings with future investigations.
\end{abstract}

Keywords. Remembrance, auto-interview, earthquake, affected, inequality. 


\section{Un terremoto: como un espacio privilegiado para observar y registrar}

La ocurrencia de un terremoto de gran escala el 27 de febrero de este año trajo a la memoria de los chilenos recuerdos y remembranzas de otros terremotos vividos varias años atrás en el país y recientemente en otros países: Haití en noviembre de 2009, Tocopilla en el 2005, el terremoto del año '85 que tuvo como epicentro el puerto de San Antonio y el terremoto de Valdivia ocurrido en el mes de mayo de 1960, fueron algunos de los hitos y más recordados y rememorados tras la ocurrencia de este megasismo. En las semanas posteriores al terremoto, los medios de comunicación rescataron imágenes, entrevistas, registros de audio y fotografías de archivo que nos recordaban dichas tragedias y vinculaban estas experiencias con los sucesos recientemente vividos en el país. La mayor parte de los contenidos presentados hacían hincapié en las consecuencias o efectos que dichos terremotos tuvieron en la vida de las personas y localidades más afectadas. Por su parte, los centros académicos y de investigación también hicieron su particular ejercicio de memoria, recurriendo tanto a los registros de cada época, como a los datos y aprendizajes extraídos de cada una de estas experiencias con el propósito de revisar, complementar y contrastar sus análisis y consideraciones tras este último terremoto de gran intensidad.

Dada la intensidad que adquiere esta experiencia, es que en este artículo vamos a connotar el terremoto del 27 de febrero como un acontecimiento que cambia y transforma la vida de las personas, el modo como los sujetos se conciben a sí mismo y las relaciones que estos establecen con su entorno. Siguiendo a Mèlich vamos a asumir que los acontecimientos se constituyen en sí mismo en hitos o íconos, que indican un punto de inflexión en el modo de pensar, y de entender la vida humana, en relación con su entorno. Los acontecimientos han desgarrado a los hombres y a la historia, marcando sus designios. "A diferencia de los sucesos, los acontecimientos nos forman, nos transforman y en ocasiones nos deforman" (Mèlich, 2004,).

El terremoto transformó y trastocó la vida de un gran número de chilenos. Para algunos esta alteración solo duró un par de horas, cuando más algunos días hasta que lograron volver a su curso de vida normal, para otros la transformación tras el terremoto ha sido radical, trastocando sus vidas y generando una inversión de sentidos. El terremoto de febrero pasado, ha sido connotado como un acontecimiento no sólo por la magnitud que alcanzó el movimiento telúrico, ni por la amplia extensión geográfica involucrada, sino por los efectos y consecuencias económicas, sociales y culturales que este seísmo provocó en la vida de las personas. Nadie queda indiferente tras un acontecimiento, todos de un modo u otro, con distintos alcances y de distinta forma nos vimos impactados por esta vivencia que deja huella y marcas, algunas claramente más reconocibles que otras. Como esta premisa, nos propusimos hacer un ejercicio que rescatara la memoria de un grupo de personas que experimentaron esta vivencia y que tres semanas después del terremoto la plasman en un trabajo que nace en el contexto de una cátedra universitaria.

Si bien no es objetivo de este trabajo analizar las situaciones que el terremoto contribuyó a develar, el ejercicio que en este artículo se comenta nace con un doble propósito. Por una parte, interesaba preservar la memoria de quienes vivieron la experiencia, reconstruyendo los relatos y visiones intercambiadas cotidianamente en los días siguientes al terremoto e intencionando para ello la elaboración de un testimonio que documentara y registrara lo acontecido. El ejercicio también buscaba instalar las bases de una perspectiva comparada que sirviera a los objetivos del curso que, entre otros contenidos, analiza las perspectivas de desigualdad social y pobreza; guiado por este último propósito se intencionó una perspectiva de análisis que buscaba profundizar en las subjetividades, percepciones y visiones de quienes pese a la fuerza del terremoto resultaron ilesos o sin consecuencias, y quienes por distintas situaciones económicas, sociales y culturales o condiciones personales son connotados como afectados.

Diversos artículos académicos, notas de prensa e informes institucionales dieron cuenta de las situaciones de desigualdad y pobreza que quedaron develadas tras el terremoto pasado. Además de dejar en evidencia las debilidades institucionales, las disparidades en el desarrollo, y la falta de planes de acción ante emergencia de este tipo, interesaba aproximar a los estudiantes a un debate en torno a las configuraciones sociales que conforman la sociedad chilena y los quiebres o fracturas sobre los cuales estas configuraciones se estructuran. El informe elaborado por el PNUD (2010) a propósito del terremoto ilustra con bastante claridad este punto cuando señala 'que la vulnerabilidad post-terremoto evidenció fracturas importantes en el tejido social, dejando a la vista la carencia de inclusión social de ciertos grupos de la población al desarrollo. Los grupos sociales más desfavorecidos pertenecientes a los estratos sociales más pobres, viven esta 
falta de inclusión a través de baja participación democrática, con necesidades básicas insatisfechas y con dificultad de acceso al trabajo y a los beneficios del desarrollo que otros grupos sociales del país disfrutan. Son justamente estos grupos los que deben recibir especial atención en una situación de crisis como la enfrentada por Chile, debido a la desolación y abandono que pueden enfrentar en el contexto de desastre'.

Joaquín García Roca acentúa el carácter dinámico de la actual configuración social que no sólo caracterizan al país, sino a las sociedades contemporáneas, cuando subraya la facilidad con la que se transita de una zona a otra: "Basta un pequeño movimiento a la zona de la vulnerabilidad para que se caiga de lleno en la exclusión (...) La zona de la vulnerabilidad está minada de dificultades que conducen a la exclusión social; la barrera que separa una zona de otra es muy frágil y tenue" (1998, p. 134 y 135). Si en la reflexión de este autor los tenues movimientos pueden ser los desencadenantes de un estado de exclusión o de riesgo de ella, los movimientos intensos como los provocados por el terremoto y sus réplicas económicas y sociales pueden agudizar e incluso perpetuar la situación de aquellos ubicados en la tenue y líquida frontera física y simbólica que acompaña a la representación espacial de las exclusiones y la pobreza.

El desamparo, abandono y soledad que acompañó a los afectados en los días previos al terremoto, activó en varios de los participantes en este ejercicio visiones que homologan esta situación a las experiencias más cruentas de exterminio y muerte. Las imágenes de campo de batalla, aniquilación y devastación de quienes fueron víctimas de este acontecimiento trajeron a la memoria que el mundo de los excluidos es donde se hace la experiencia de la muerte, de la inexistencia, de la nada. "Dante hubiera tenido problemas para creer lo que sus ojos veían" es la expresión que utiliza el criminólogo Nils Christie cuando describe la situación de exclusión e inhumanidad que viven los presos de una cárcel de Sao Pablo (2004, p.46) y que hoy hemos tomado para connotar las impresiones que el terremoto y principalmente el tsunami dejó entre los que lo sobrevivieron y entre quienes, a la distancia, fuimos testigos de sus profundos efectos en la vida de los pequeños pueblos de la costa de la sexta y séptima región y sus habitantes.

Si bien esta reflexión no forma parte sustancial de este artículo, nos pareció pertinente incorporar una perspectiva de análisis que se transforma en el impulso inicial de un curso que analiza las pobrezas y desigualdades sociales y que parte reflexionando en torno a desastres y catástrofes como la acontecida por un terremoto que tras algo más de 3 minutos de duración dejó en evidencia otros fenómenos o problemáticas que habían permanecido por largo tiempo invisibles.

\section{El sentido de rescatar la memoria y la experiencia vivida tras el terremoto}

Revisemos a continuación los fundamentos que sostienen el primero de los objetivos propuesto en este ejercicio de curso y que dan cuenta del sentido y la relevancia de rescatar la memoria que surge tras un acontecimiento como el que aquí se aborda. Acontecimiento que es singular y personal para cada uno pero, al mismo tiempo, un suceso colectivo que se puede encontrar en la vivencia y en la experiencia de una comunidad ampliada. Por lo mismo, resultó particularmente interesante intencionar este esfuerzo de reconstrucción en la medida que esta experiencia no está determinada previamente, si bien los actores contaban con algunos referentes, su carácter originario y original -para muchos sujetoslo constituye en un suceso único y en este sentido histórico.

Es el carácter histórico de este suceso el que motiva la realización de este ejercicio pedagógico que se vincula a otras líneas de investigación y de estudios que se proponen rescatar la memoria individual y colectiva que surge tras un acontecimiento, por su capacidad de alteración de las bases y fundamentos de una sociedad determinada. Tomando en cuenta la dinamicidad de lo experimentado tras el terremoto y los múltiples sucesos que le acompañaron en los días siguientes, se toma la opción de iniciar este trabajo de documentación lo más tempranamente posible siguiendo las recomendaciones que en su momento hiciera Jean Carles Mèlich en su artículo "Narración y Hospitalidad" cuando puntualiza: "El olvido hace su trabajo cada mañana, pero también cada mañana, tenemos la capacidad de rememorar la experiencia, de romper el presente y anticipar el futuro" (2000, p. 139).

Es esta rememoración la que se ha intencionado en este trabajo, que toma como base la pregunta base compartida por un gran número de personas en los días posteriores al terremoto y cuya respuesta fue compartida con unos y otros en distintos contextos y espacios. ¿Dónde estabas para el terremoto? Se constituye entonces en la pregunta que guío este trabajo y que actúa como impulso inicial para desencadenar una serie de recuerdos e imágenes vinculadas. 
Se trataba de luchar contra el tiempo y el olvido por eso los estudiantes reciben la invitación de construir sus relatos de terremotos el primer día de inicio de clases, de un año académico también marcado por este acontecimiento que llevo a distintas universidades, centros de formación y establecimientos educacionales a revisar sus formas de enseñanzaaprendizaje, sus protocolos de actuación en caso de catástrofe y el modo como se abordan acontecimientos de este tipo ${ }^{1}$.

"Vivimos en un tiempo de olvido de la narración. Y este olvido es una muestra más de la negación del Otro" (2000: 138), dice también Jean Carles Mèlich en su artículo ya mencionado. Tomando los planteamientos de este autor, en esta aproximación vamos a considerar que la crisis de la narración, implica una crisis de la experiencia y del testimonio de aquellos que han vivenciado un determinado acontecimiento. En el ensayo titulado "El narrador", Walter Benjamin relaciona esta crisis de la narración con la irrupción de una forma de comunicación típicamente burguesa: la información. Esta, a diferencia de la narración, no necesita de la experiencia. Lo que resulta interesante aquí es darse cuenta de que la narración, la experiencia narrada vive en un proceso de transmisión. El narrador, dice Benjamín, "toma lo que narra de la experiencia, la que el mismo ha vivido, o bien la que le han transmitido. Pero a su vez, hay narración en el momento en que esta experiencia vuelve a ser transmitida". Por eso, advierte "esta experiencia de narración, se torna a su vez en experiencia vivida, para el que la escucha, para el que la oye" (1999, p. 8-9).

El carácter actualizante de la narración, es lo que permite que quien escuche, viva otra vez la experiencia. Y en este sentido podríamos decir que el oyente es capaz de recordar lo que no ha vivido, la experiencia que no ha experimentado, pero que le ha sido transmitida en el relato.

Como una forma de poner en contexto y otorgar un marco de análisis a esta narración se propone a los estudiantes desarrollar un ejercicio de obser- vación de sus experiencias y actuaciones ocurridas tras el terremoto acontecido hace tres semanas atrás. Para ello, los alumnos trabajan individualmente en un registro de autoentrevista que luego fue complementado con la entrevista a una persona afectada por el terremoto en cualquiera de sus dimensiones: personales, sociales, económicas productivas, entre otras.

\section{La activación de la memoria por medio de un testimonio narrativo que intenciona tres momentos: antes, durante y después del terremoto}

Se propone a los estudiantes desarrollar primero una exploración individual que además de rescatar la vivencia, dejara en evidencia los supuestos y los marcos interpretativos desde donde cada uno se sitúa para aproximarnos a un determinado fenómeno, en este caso el terremoto recién pasado. El ejercicio propuesto consiste en trabajar dos técnicas simultáneamente -observación ${ }^{2}$ y entrevista- como un modo de inscribir las percepciones y representaciones acerca de un ámbito determinado.

Como primer paso se propone desarrollar una autoentrevista que reconstruye la experiencia vivida en el terremoto por cada alumno y que explora al mismo tiempo en los referentes y perspectivas que de esta experiencia surgen. Para realizar esta entrevista se siguen esencialmente las directrices y orientaciones desarrolladas por Miguel Valles y Alejandro Baer (2005) en su artículo "Investigación social cualitativa en España: pasado, presente y futuro. Un retrato" las que se suman a un esquema seguido en una investigación posterior desarrollada por la profesora del curso ${ }^{3}$. Tomando en cuenta lo anterior se propone a los alumnos realizar una entrevista biográfica o autoentrevista, siguiendo los lineamientos sobre etnoentrevista y autobiografía proporcionados por Alsop (2002) y Boufoy-Bastick (2004), así como el trabajo de Philippe Lejeune, publicado originalmente en 1975.

1 No podemos partir el año como si no hubiera pasado nada, fue la máxima que compartimos profesores, estudiantes, apoderados y administrativos de los distintos centros de enseñanza del país. Algunos claramente debieron retrasar el inicio del año escolar por varias semanas dado que presentaban importantes daños en su infraestructura y la comunidad escolar se encontraba seriamente afectada por el terremoto y el tsunami, otros que no sufrieron daño o este era claramente insignificante sentían que debían hacer algo, dando impulso y albergando una diversidad de iniciativas y acciones orientadas a actuar ante la emergencia vivida y atenuar sus efectos.

2 La observación fue entendida en este ejercicio como un primer modo interpretativo y que desarrolla la capacidad de ver cada vez más en una actitud de vigilancia permanente sobre las propias representaciones (De Tezanos, 1995).

3 En este trabajo se intenciona un esquema de rescate de memoria que toma como estructura conversacional el eje biográfico (pasado, presente y futuro) que va indagando en los fundamentos y motivaciones que llevaron a un grupo de profesionales a desarrollar un quehacer determinado. 
La autoentrevista tenía como principal propósito activar la memoria y las impresiones de quienes vivieron el terremoto reciente, conectando y vinculado dicha vivencia con los referentes y elementos que a cada uno de daban sentido, así como las proyecciones y reflexiones que de esta experiencia se devienen. Bajo el supuesto que indicaba que analizando el pasado podemos entender mejor el futuro, interesaba abrir un espacio, de carácter plural para la reflexión sobre el lugar que alcanza hoy el acontecimiento del terremoto y sus consecuencias en la vida de las personas y la sociedad en su conjunto, por ello la importancia de recordar la mayor cantidad de elementos de dicha vivencia contar y con registros narrativos de esas experiencias.

En la narración la memoria es su fuente de vida, señala Benjamin. "La narración necesita de la memoria porque para poder narrar hay que retener la experiencia vivida para seguir contándola (...) porque sin esta constante transmisión no hay ninguna posibilidad de narración" (Mèlich, 2000: 133). La narración hace posible descubrir la singularidad de cada uno, pero no una singularidad independiente de los otros, sino una singularidad heterónoma, diremos en este trabajo y por ello la importancia de considerar en esta narración perspectivas comparadas.

Desde el punto de vista de este trabajo, la identidad aparece como identidad narrativa. Lo que interesa es la narración que los sujetos hacen de un acontecimiento determinado y que registra lo vivenciado por cada uno al momento de experimentar el movimiento telúrico de 8,8 grados en la escala de Ritcher que afectó la zona centro sur del país. La identidad narrativa, en este caso está considerada en el sentido de una categoría dinámica e históricamente situada en un momento determinado que se circunscribe inicialmente a lo acontecido en las 24 horas posteriores al terremoto.

El relato de lo acontecido en ese período de tiempo es escrito por cada estudiante en primera persona, generando un texto autobiográfico que registra las acciones y emociones que se desencadenaron luego de las 3:34 de la mañana del día sábado 27 de febrero. Se optó por trabajar dichos textos como testimonios autobiográficos y no como relatos o historias de vida, "por cuanto hace referencia 'al material cualitativo elaborado a la manera de algunas de las modalidades de historias de vida, que suponen el anonimato de los protagonistas" (Valles, 2007 p. 16).

En el caso de este ejercicio la noción de testimonio se utiliza con el propósito de develar experiencia o vivencia de un grupo de sesenta estudiantes universitarios, todos menores de 25 años, cuya experiencia puede representar a una comunidad más amplia. Se asume de este modo la concepción de Denzin $\&$ Lincoln quienes a propósito del trabajo de John Beverley "Testimonio, Subalternity, and Narrative Authority" señalan: "a diferencia de la autobiografía, el testimonio implica un borrado del concepto de autor. El testimonio usa una voz que representa a un conjunto más amplio. Esto crea una forma democrática e igualitaria de discurso. El testimonio es una obra abierta, interpretativa (...) En este sentido, el testimonio es un objeto de interpretación; no es un espejo del mundo" (2005, p. 383). Y es ese precisamente el carácter que asumen estos registros autobiográficos.

Este testimonio es identitario reafirmaremos en este artículo, dado que se construye a partir de los retazos y vivencias experimentadas durante el terremoto por cincuenta y seis estudiantes universitarios chilenos y cuatro estudiantes de intercambio. Como se ha señalado, independiente de su nacionalidad ninguno de ellos habían experimentado un fenómeno de similar magnitud y sólo contaban con las referencias y consideraciones que en algún momento habían recibido de sus mayores: padres, abuelos, profesores, entre otros.

Para el desarrollo de este concepto de identidad hemos seguido las reflexiones de Daniel Innerarity quien señala que el sujeto "debe integrar sus acciones en su propia biografía, con este acto el sujeto se convierte, entre otras posibilidades en "biografía electiva" (Levi 1984), en "biografía reflexiva" (Giddens, 1991), "biografía de bricolage" (Hitzler, 1988) o en identidad de retazos" (Heiner Keupp, 1994)" (Innerarity, 2001, p. 45). Las identidades contemporáneas tendrían más de retazos y fragmentos, que las identidades electivas afirma este autor. Con esta metáfora se quiere connotar que las identidades actuales están en proceso de transformación constante, lo que resulta especialmente pertinente cuando se analizan los testimonios de este grupo de jóvenes que en su mayoría se encuentran finalizando una fase de formación profesional y están próximos a egresar de una carrera de pregrado. Lo que antes era un determinado modo de ser, puede ahora verse cuestionado cuando sus componentes esenciales se analizan bajo la perspectiva que ofrece un nuevo contexto o modo de entender.

Tomando en cuenta esta posibilidad es que se consideró relevante indagar no sólo en lo acontecido durante el terremoto, sino en las posibilidades y perspectivas que surgen luego de su vivencia. En un 
ejercicio prospectivo que invitaba a los estudiantes a imaginar distintos escenarios futuros y a situarse en un eje temporal de un par de años más cuando esta experiencia se configurara sólo como un recuerdo. Del mismo modo como se intenciona una narración prospectiva, se optó a por una modalidad de rescate que recogiera también en la autoentrevista los referentes previos que se encontraban presentes en la biografía de cada estudiante y las significaciones que un acontecimiento de este tipo puede significar cuando se consideran elementos pasados. Con este doble movimiento que anticipa y retrocede se reconoce que los procesos de individuación que caracteriza a las sociedades contemporáneas origina una fragilización de las construcciones identitarias de los individuos.

Cada vez los sujetos son más libres, pero al mismo tiempo, necesitados y dependientes de otros para conformar su identidad. Así se connota cuando se observa que la mayor parte de los testimonios sobre lo acontecido en el terremoto se construyen a partir de las visiones, imágenes y emociones que generó el hecho de estar cerca o lejos de la familia o de quienes son connotados como significativos en la vida de cada uno: las referencias a abuelas y abuelos, tías, primos, padres, hermanos, novios e hijos inundan los relatos de los estudiantes y dan cuenta de la importancia de significar esta experiencia junto a quienes se consideran cercanos. Recurrimos nuevamente a Daniel Innerarity para reafirmar esta visión cuando señala "Vivimos historias ya comenzadas. Vivir es incorporarse a lo que está pasando (...) la iniciativa humana no es absoluta (...) Buena parte de lo que sabemos se lo debemos a otros (...) No hay acción humana con pretensiones de relevancia histórica que pueda prescindir de la colaboración de otros, que no sea una cierta continuación de lo que otros hicieron o una preparación para lo que otros llevarán a término" (2001, p. 103).

¿Qué sabían los entrevistados de los terremotos?, ¿de qué modo se incorpora en sus biografías esta experiencia vicaria?, ¿cómo se significan estos y otros acontecimientos en los itinerarios de cada uno?, ¿qué se espera en el futuro? Fueron algunas de las interrogantes que esta indagación testimonial buscaba develar, y que nos aproximan a un entramado que devela las conexiones, vinculaciones y redes afectivas y de sentido presentes en cada uno de los testimonios autobiográficos.

Con ello hacemos explícito que en este esfuerzo entendemos la reconstrucción de los relatos y su posterior conformación en testimonios como una obra colectiva de generación de conocimiento, que se enraíza en vivencias y experiencias biográficas determinadas, y en algún sentido únicas e individuales, pero donde es posible rastrear la incidencia y las relaciones que se originan entre los sujetos, así como de contextos socio-históricos que la determinan. Como señalamos en el punto anterior, con ello este trabajo se inscribe en aquellas líneas investigativa que luchan explícitamente por anticiparse al olvido, rescatar y reconstruir la memoria de quienes fueron protagonistas de un determinado suceso social, que no se circunscribe solo a la experiencia de este terremoto, sino a otros acontecimientos que le precedieron así como los que están por venir.

Las palabras de Wielse y Metz (1996) en torno a cultura narrativa resultan especialmente movilizadoras para este trabajo que se formula un objetivo un tanto inusual, cuando se propone activar y rescatar procesos, discusiones y reflexiones que se gatillaron tras el terremoto. "Una cultura no quiere caer en la amnesia, una cultura que no quiere perder del todo la memoria que ha marcado su vida, ha de poseer siempre, entonces, una especie de cultura narrativa (1996: 49).

Son los fundamentos que dan cuenta de la existencia de esta cultura narrativa, los que nos llevan a plantear que las narraciones que relatan la forma como se vive un determinado acontecimiento, nos pueden ayudar a comprender mejor el sentido y los alcances que hoy en día enfrentan quienes asumen algunas de las tareas vinculadas a la reconstrucción y reparación del daño causado, así como los desafíos y tendencias futuras en materia de prevención y protección de las personas. Por lo mismo, es posible encontrar en esta propuesta de indagación, un esfuerzo explícito por rescatar la memoria histórica, pero también sentimental e identitaria de un grupo de jóvenes universitarios quienes en su mayoría experimentaban por primera vez un acontecimiento de este tipo.

\section{La construcción de testimonios de quienes se vieron afectados por el terremoto y un esfuerzo por desarrollar un análisis comparado}

Como estaba en el horizonte de este trabajo la perspectiva de la desigualdad se intencionó además de la autoentrevista y la construcción del testimonio autobiográfico que los estudiantes recogieran y reconstruyeran la perspectiva de una persona que se vio en alguna medida afectada por el terremoto. El propósito original buscaba contrastar y generar conexiones entre la vivencia personal de cada alumno 
y lo narrado por quien se vio alterado de manera más radical por el terremoto o sus consecuencias más directas.

Las orientaciones seguidas para la elaboración de la autoentrevista y los ejes que intencionaban una reflexión en torno al pasado, presente y futuro, fueron repetidas en este segundo acercamiento que se aproximaba a la vivencia de otro. Si bien se esperaba -aunque no se explicitó- que los estudiantes construyeran los relatos de un otro distinto de si, la mayor parte de ellos recurrieron a quienes le eran próximos o cercanos, entregando con sus testimonios posibilidades de análisis hasta ese momento no contempladas como ocurre con la perspectiva intergenacional, que permite la profundización y exploración del enfoque biográfico en distintas ramificaciones familiares, vecinales o locales.

Lo anterior si bien resultó sorprendente, dado los objetivos propuestos, reafirma nuestro interés por el enfoque biográfico, en la medida que éste se desarrolla a partir de los testimonios y narrativas recogidas desde los propios sujetos, que en muchas ocasiones fueron complementadas y completadas por los relatos de quien se concibió como afectado por el terremoto. Los testimonios construidos ganan en complejidad y en potencial analítico cuando se leen a dos voces, como ocurre en el caso de: abuelo-nieto; padre-hijo; hermanos; novios o parejas; tíos-sobrinos. Lo anterior nos permite reafirmar que se trata de una metodología cualitativa, que considera la singularidad y la heterogeneidad de las situaciones individuales, pero que al mismo tiempo permite la aparición progresiva de elementos de análisis, de procesos comunes que estructuran y organizan a determinados colectivos, como ocurre en este caso con dos o más generaciones de familias muchas de las cuales tienen sus orígenes y descendientes viviendo en las localidades que se vieron más afectadas por el sismo.

Dado que los estudiantes podían entrevistar a un afectado en cualquiera de sus dimensiones, la elección de un testimonio cercano hizo que predominaran en los testimonios de los afectados las alusiones y referencias relacionas con los efectos emocionales y psicológicos que el terremoto significo para los entrevistados. De los 60 testimonios construidos por los estudiantes a través de entrevistas biográficas, 23 entrevistados se autodefinen emocionalmente afectados tras el terremoto y todos corresponden a familiares directos, vecinos, amigos o parejas de los alumnos. Los 11 entrevistados que no se consideran afectados, pero cuyos relatos fueron considerados también corresponden principalmente a cercanos y próximos de los alumnos. De estos testimonios se rescata el efecto de unir personas que intencionó este trabajo narrativo que reconstruye las vivencias del terremoto de un grupo de personas que, pese a estar cerca físicamente, no habían compartido sus vivencias e impresiones sobre este acontecimiento. A diferencia de las narraciones anteriores, otros 23 testimonios de afectados incluyen en su narración secuelas y efectos físicos del terremoto, la mayor parte de ellos sobre sus viviendas y residencias habituales o de descanso. 13 testimonios corresponden a familiares directos o conocidos de los entrevistados que viven o vivían en las localidades cercanas al epicentro del sismo o en la costa arrasada por el tsunami: Duao, Doñihue, Cahui, Cauquenes, Curanipe, Putu, Lo Miranda y Rancagua, son algunas de los lugares de residencia de quienes aportan con su testimonio a este trabajo. Por su parte, los 10 entrevistados que no tienen cercanía con los estudiantes corresponden a habitantes de las localidades de Alhue, Curepto y Hualañe entre otras, donde los alumnos realizaron trabajos como voluntarios y donde tuvieron la oportunidad de conocer y registrar las vivencias de un grupo de personas cuyo relato deja huella y permite su posterior reconstrucción como testimonio.

"Las narraciones pueden hacernos comprender", dice Susan Sontag (2003:116), y en esta perspectiva se inscriben los relatos y las historias recogidas a través de los testimonios. Los relatos y las historias nos ayudan a sanar, agregamos en este artículo cuando se observa el quehacer de estos estudiantes mientras realizaban labores como voluntarios, su acercamiento a las vivencias de otros y el relato de sus vivencias, les permite resignificar y profundizar lo acontecido. Independiente de sus alcances, los testimonios construidos por los estudiantes, permiten que el lector se introduzca narrativamente en la vivencia de cada persona y sienta el impacto de ese acontecimiento y así, juntos, podamos sentir vivencialmente el alcance de su significado.

Robert Wuthnow reflexiona en Actos de Compasión acerca de la importancia de las narrativas y la posibilidad de contar historias, que entiende como un componente esencial del humanismo y del interés por los demás. Este autor valora esencialmente esta posibilidad que permite a los entrevistados 'contar sus historias con sus propias palabras' (1996, $114 \mathrm{y}$ 115), lo que agrega una especie de carácter tangible, color y textura a la discusión teórica y conceptual que hasta antes de este acontecimiento se podía desarrollar en torno a las nociones de desigualdad, pobreza, exclusión e intervención social. 
El terremoto no fue una guerra mundial pero sus efectos y consecuencias para muchos son semejantes. Además de la devastación mencionada en los puntos anteriores, varios relatos autobiográficos vinculan lo acontecido en los días posteriores con imágenes y visiones que dan cuenta de la falta de seguridad y la pérdida de referentes. El miedo y la sensación de vulnerabilidad es uno de los aspectos más connotados por los entrevistados de los estudiantes, cuyos relatos y narraciones complementan y dan profundidad a este ejercicio escolar.

Tras lo acontecido en Chile el día 27 de febrero, las reflexiones de Urlich Beck en torno a sociedad de riesgo adquieren un significado más preciso, a propósito de su reflexión en torno a las fases de la postguerra este autor puntualiza en "Hijos de la Libertad" "se produce el retorno de la incertidumbre, no sólo en el sentido de que se pierde la confianza en que las instituciones clave del mundo industrializado -economía, derecho y política- estén en condiciones de contener y controlar las consecuencias (...) sino (...) que (...) las biografías del bienestar se conviertan en biografías de riesgo, que pierdan la seguridad material futura y la identidad social." (Beck, 1997, p.23).

\section{La relevancia de indagar en la 'memoria narrativa' y los aportes de esta perspectiva al trabajo social}

Desde hace ya varios años, las perspectivas narrativas y los métodos que recurren a las narraciones han adquirido un gran realce en las ciencias sociales (White y Epston 1993; Hall, 1997; Wengraf, 2001; Chamberlayne, Rustin y Wengraf, 2002); como consecuencia de la revitalización de los enfoques de investigación cualitativos y el redescubrimiento de las perspectivas biográficas que inscribe los sucesos y fenómenos analizados en los itinerarios de personas y comunidades concretas. También la narración ha experimentado una singular fuerza como consecuencia de aquellos enfoques y perspectivas sociohistóricas que se proponen rescatar la memoria y, por lo mismo, las experiencias vicarias de quienes han protagonizados los grandes acontecimientos de nuestro tiempo.

Este artículo encuentra sintonía con lo planteado por Jesús Conill en Ética y Hermenéutica, cuando argumenta que "la razón experiencial es más sensible a las situaciones vitales concretas de pobreza, miseria y opresión. Sólo por una experiencia básica de reconocimiento recíproco, de una intersubjetividad vital (y no sólo reflexivo-formal), reconocemos a los afectados, a los sujetos sufrientes desde ellos mismos y sus situaciones, en su cruda realidad (...) donde se vive, se experimenta, se palpa, se siente, el poder de lo real, al margen de cualquier mediación manipuladora. Es precisamente en la comunidad de vida y de sufrimiento, en la que ha incidido la ética de la liberación, y a la que aporta valiosas contribuciones filosóficas, tanto la hermenéutica experiencial como el análisis noológico del fondo sentiente -sufrientedel poder de lo real." (Conill, 2006, p.278-279).

Para Conill atender a las experiencias nos hace más sensibles a las vidas concretas de los otros, a sus voces, a sus singularidades. Consiste en una primera característica de la narratividad: precisamente narrar es la situación de relatar algo y esa situación incluye a todos los actores que participan, al contexto y los acontecimientos traídos a ese momento. La perspectiva narrativa, agrega Fernando Vidal en su libro Pan y Rosas "nos obliga a estar atento a las personas y las historias son inseparables de las personas y hechos que las protagonizaron. Frente a categorías abstractas que es fácil hacer que no sean de nadie y, finalmente, puedan no ser "para nadie", la narratividad siempre nos muestra que el relato es siempre relato de alguien para alguien. La narratividad no solamente nos habla de un relator de origen, de alguien que vivió esos acontecimientos sino que nos habla -y esto no siempre se valora- de alguien que es destinatario de esa narración y al que se dirige el que relata $(2009$, p. 85).

Desde nuestra perspectiva, este interés por el rescate narrativo de la memoria histórica y sentimental de quienes han experimentado el mal social, puede ser visto como la contracultura de aquellas dinámicas y procesos sociales que abogan tanto por la objetividad o cientificidad del conocimiento, como por la instantaneidad de éste y que nos llevan a concebirlo como un pasado sin historia.

Consideramos que una aproximación narrativa a lo acontecido tras el terremoto, nos permitiría lograr un mejor conocimiento de sus dinámicas y alcances, que nos conduzca a promover y a desarrollar prácticas de trabajo social y de reconstrucción que consideren las perspectivas de sus protagonistas. Aproximación, que como ha quedado en evidencia en este trabajo, posee un posicionamiento hermenéutico y un enfoque interpretativo particular, que permiten integrar y articular elementos diversos con el propósito de perturbar el acceso a la verdad o al menos hacerla menos ingenua. En este esquema de pensamiento, el conocimiento es concebido como un proceso que avanza en interpretaciones y reinterpretaciones sucesivas, $y$, en este sentido, toda 
comprensión, toda interpretación, es esencialmente circular y por lo mismo dialógica.

Es desde esta forma de entender el conocimiento que proponemos considerar los testimonios que fueron recogidos en este ejercicio de curso, como portadores de experiencias que no buscan resolver un problema, sino provocar que el ser humano se enfrente a las cuestiones fundamentales de su existencia. Con la inclusión de esta perspectiva narrativa, queremos instar a desarrollar una práctica de intervención en Trabajo Social imaginativa y alterada, que perciba y trate a los sujetos como protagonistas de los procesos sociales en los que están insertos y no como afectados o ilesos, ni como implementadores o clientes de determinadas acciones.

Christopher Hall, en su libro Social Work as Narrative, presenta al trabajador social como una persona que interviene con el material primario de los relatos de las personas y habla del empoderamiento que adquiere la persona cuando se convierte en un narrador, "the empowering of the storyteller" (Hall, 1997: p.249), lo que se narra es precisamente la experiencia y ello nos devuelve al propósito inicial de este artículo que destaca la perspectiva experiencial de este acontecimiento.

Necesitamos desarrollar el Trabajo Social narrativo, afirma en forma convincente Fernando Vidal, para posteriormente puntualizar: "Podemos identificar el Trabajo Social narrativo con una serie de técnicas, pero lo más importante sería encontrar la dimensión creadora de sentido que tiene cualquier tipo de técnica de intervención. El Trabajo Social no crea y comunica "contenidos" de sentido solamente cuando hace actividades narrativas o reivindica sino que donde principalmente comunica es en su forma de hacer (...) La pregunta no es si hacemos actividad prestacional o reivindicativa sino que el interrogante sería: ¿los servicios que hacemos tienen sentido? ¿Hasta dónde alcanza el sentido de lo que hacemos? (...) debemos intensificar el sentido y expresividad de lo que hacemos" (Vidal, 2009: 335).

El Trabajo Social narrativo es aquel que incorpora a la metodología de intervención social la activación de los significados y relatos como recursos de empoderamiento de sujetos. Hay diversas experiencias en distintas disciplinas y esta ha sido una forma de comunicar y difundir una de ellas.

\section{Bibliografía}

BOUFOY-BASTICK BÉATRICE. (2004), January). AutoInterviewing, Auto-Ethnography and Critical Incident Methodology for Eliciting a Self-Conceptualised Worldview [36 paragraphs]. Forum Qualitative Sozialforschung / Forum: Qualitative Social Research [On-line Journal], 5(1), Art. 37. Disponible en: http://www.qualitative-research.net/fqs-texte/1-04/1-04boufoy-e.htm [Fecha de consulta: 01/02/08].

DENZIN, NORMAN K. \& YVONNA S. LINCOLN. (2005). (Eds.) The Sage Handbook of Qualitative Research, Thousand Oaks: Sage Publications (Original de 1994).

CHAMBERLAYNE, PRUE; MICHAEL RUSTIN y TOM WENGRAF (2002) Biography and Social Exclusión in Europe, Bristol: The Policy Press.

HALL, CHRISTOPHER. (1997). Social Work as Narrative, Vermont: Ashgate Pu. Co. (Original de 1993).

LEJEUNE, PHILIPPE. (1994). El pacto autobiográfico y otros estudios, Madrid: Meazul-edymion (Original de 1975 Le Pacte autopiographique, Editions du Senil).

PNUD. (2009). Desarrollo Humano en Chile. La manera de hacer las cosas Programa de las Naciones Unidas para el Desarrollo (PNUD) Santiago de Chile, enero 2009.

REED-DANAHAY, DEBORAH. (1997). Auto/Ethnography, New York NY: Berg.

SONTAG, SUSAN. (2003). Ante el dolor de los demás, Barcelona: Ediciones Alfaguara.

VALLES, MIGUEL \& ALEJANDRO BAER. (2005). Investigación social cualitativa en España: pasado, presente y futuro. Un retrato in Forum Qualitative Sozialforschung / Forum: Qualitative Social Research [On-line Journal], 6(3), Art. 18. Disponible en: http://www.qualitativeresearch.net/fqs-texte/3-05/05-3-18-e.htm [Fecha de consulta: 15/03/07].

VALLES MARTÍNEZ, MIGUEL. (2007). "Metodología biográfica y experiencia migratoria: el enfoque de los testimonios anónimos y de autor en el legado y la estela de Juan F. Marsal", comunicación presentada al IX Congreso Español de Sociología de la FES, Barcelona, septiembre de 2007. [Fecha de consulta: 13/12/07].

WENGRAF, TOM. (2001). Qualitative Research Interviewing: Biographic Narratives and Semi-structured Method, London: Sage.

WHITE, MICHAEL y DAVID EPSTON. (1993). Medios narrativos para fines terapéuticos, Barcelona: Paidós (original de 1980).

WHYTE, WILLIAM FOOTE. (1971). La Sociedad de las esquinas, México: Editorial Diana (Original de 1943 Street Corner Soviet, Chicago: The University of Chicago) Género y sequía: experiencias de Mujeres Australianas en la sequía de 1990. Gender and Drought: Experiences of Australian Women in the Drought of the1990s. 